\title{
Development and validation of HPLC method to measure active amines in plant food supplements containing Citrus aurantium $\mathrm{L}$
}

\author{
Chiara Di Lorenzo, Ariana Dos Santos, Francesca Colombo, Enzo Moro, Mario Dell'Agli, \\ Patrizia Restani*
}

Dipartimento di Scienze Farmacologiche e Biomolecolari, Università degli Studi di Milano, Via Balzaretti 9, 20133 Milan, Italy

\section{A R T I C L E I N F O}

\section{Article history:}

Received 6 February 2014

Received in revised form

11 April 2014

Accepted 12 May 2014

Available online 21 May 2014

\section{Keywords:}

Synephrine

Citrus aurantium

HPLC

Adrenergic amines

Plant food supplements

\begin{abstract}
A B S T R A C T
Citrus aurantium L. (bitter orange) is frequently used as an ingredient of food supplements aimed to reduce body weight or improve general physical performances. The most active compounds of C. aurantium are amines having adrenergic activity: octopamine, synephrine, tyramine, N-methyl-tyramine and hordenine. The quantification of these amines is critical since their content in food supplements is regulated by national/international rules. Some methods for the quantification of $C$. aurantium amines have been published, including the official method developed by AOAC, but most of them are not totally satisfactory for the analysis of complex matrixes, such as extracts or food supplements.

A new HPLC-UV-fluorescence procedure has therefore been developed; the method is quick and simple, and allows the analysis of samples after a rapid extraction procedure without any further cleaning step. The assay, using one or two detectors, showed good results during the validation tests performed according to the FDA guidelines.
\end{abstract}

() 2014 Elsevier Ltd. All rights reserved.

\section{Introduction}

Botanicals and botanical preparations are widely consumed in Western diets from various sources; among them plant food supplements (PFS) are the most important. Unlike drugs, these products are generally perceived positively by consumers, since "natural" is often considered synonymous with safety (Hung, Hillier, \& Ernst, 2011).

The popularity and the ease of access in shops or via the Internet have made for rapid diffusion of these products, and there are concerns about their quality, composition, and safety. The problem is particularly significant, when they are obtained from unregulated markets where illicit activities are not infrequent (Angell \& Kassirer, 1998; Gurley, Gardner, \& Hubbard, 2000).

Labeling of PFS is a further problem, since the accuracy of the declared composition requires reliable analytical methods (Gurley et al., 2000). Cianchino, Acosta, Ortega, Martinez, and Gomez (2008) analyzed four herbal dietary supplements aimed at weight control and identified undeclared active compound such as ephedrine and norephedrine. The claimed properties of these food

\footnotetext{
* Corresponding author. Tel.: +39 (0)2 50318371; fax: +39 (0)250318284.

E-mail address: patrizia.restani@unimi.it (P. Restani).
}

supplements derived from the illegal additions, not the declared ingredients (Gurley et al., 2000). In 2010, Vaysse et al. (2010) analyzed 20 herbal medicines and dietary supplements marketed as 'natural' slimming products; 14 of them were adulterated with sibutramine and synephrine.

Citrus aurantium L., also known as bitter orange, is a botanical ingredient frequently used in food supplements aimed at reducing body weight or improving general performance. The most important active ingredients of $C$. aurantium are amines having adrenergic activity: octopamine, synephrine, tyramine, N-methyltyramine and hordenine (Fig. 1). The C. aurantium extract is permitted in food supplements, but several countries have established limits for the content of active amines (among others Italian Ministry of Health, 2012).

The background is that the FDA's ban of ephedrine-containing supplements led to increased use of $C$. aurantium as an alternative to Ephedra, with possible risk for consumers (Haller \& Benowitz, 2000; Stohs, Preuss, Keith, Keith, Miller, \& Kaats, 2011). Quality control of PFS containing C. aurantium is therefore very important and a suitable analytical method is needed, to enable producers to check the raw material and extracts.

Several analytical approaches have been developed for the detection and quantification of the amines contained in C. aurantium. Pellati, Benvenuti, Melegari, and Firenzuoli (2002) 
<smiles>NCC(O)c1ccc(O)cc1</smiles>

Octopamine<smiles>CNCC(O)c1ccc(O)cc1</smiles>

Synephrine<smiles>NCCc1ccc(O)cc1</smiles>

Tyramine

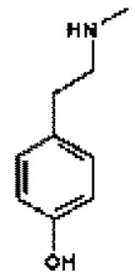

Nmethyltyramine

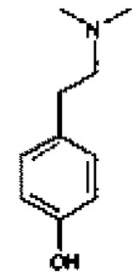

Hordenine
Fig. 1. Chemical structure of octopamine, synephrine, tyramine, N-methyl-tyramine, hordenine.

analyzed by reversed-phase only synephrine, octopamine and tyramine. Ephedrine alkaloids and synephrine were assayed using column-switching technique coupled to a cation exchange column with scanning wavelength ultraviolet and fluorescence detector (Niemann \& Gay, 2003). Penzak, Jann, Cold, Hon, Desai, Gurley, and Seville (2001) analyzed synephrine and octopamine using IPC (Ion Pair Chromatography). None of these methods, however, demonstrated the ability to analyze the compounds of interest with acceptable validation data. The AOAC official method (Roman et al., 2004) allows the separation of most Citrus amines, but there are several problems in applying this method to PFS: efficacy in resolution is incomplete, the analysis takes too long and is costly, and chromatographic performance quickly deteriorates. Among published methods, that by Putzbach, Rimmer, Sharpless, and Sander (2007) based on ion-pair HPLC and fluorimetric detection (FD) was considered the most promising, being more sensitive and specific than other methods using UV detection (Arbo et al., 2008; Gurley, Wang, \& Gardner, 1998) However, problems appeared when it was applied to complex matrices and multi-ingredient samples, in particular PFS.

Our aim was to develop a simple, inexpensive HPLC method for quality control of products containing $C$. aurantium, including PFS.

\section{Material and methods}

\subsection{Reagents and chemicals}

Standards of synephrine, octopamine hydrochloride, hordenine, tyramine and N-methyl-tyramine were purchased from Sigma-Aldrich (St. Louis, MO, USA), with purity $\geq 95 \%$. The standards were stored according to the supplier's instructions. LC-grade water, methanol and acetonitrile were purchased from Sigma-Aldrich (St. Louis, MO, USA). Other reagents including 85\% orthophosphoric acid, $0.1 \mathrm{~N}$ hydrochloric acid and sodium dodecyl sulfate were from Merck KGaA (Darmstadt, Germany).

\subsection{Instrumentation}

The HPLC equipment was from Jasco (Tokyo, Japan) and consisted of two pumps (Intelligent HPLC Pump model PU-880), a fluorimetric detector (model FP-1520), a UV/Visible detector (model UV-875) and an injection valve (Rheodyne, Cotati, CA, USA) with a $100 \mu \mathrm{L}$ loop. The ChromNAV software Jasco was used for data acquisition and processing.

\subsection{Chromatographic conditions}

The chromatographic separations were carried out on a reversed phase LiChrospher RP-18 column $(250 \times 4 \mathrm{~mm}$ ID, particle size $5 \mu \mathrm{m}$, Merck, Darmstadt, Germany) in association with a LiChrospher $100 \mathrm{RP}-18,5 \mu \mathrm{m}$ guard column, both maintained at $24^{\circ} \mathrm{C}$. The fluorescence detector was set at $270 / 305 \mathrm{~nm}\left(\lambda_{\mathrm{Ex}} / \lambda_{\mathrm{Em}}\right)$, and UV-Vis detector at $224 \mathrm{~nm}$.

Gradient elution at a flow rate of $1 \mathrm{~mL} / \mathrm{min}$ used the following mobile phases: A, $2.9 \mathrm{~g} / \mathrm{L}$ sodium dodecyl sulfate in water adjusted to $\mathrm{pH} 4.2$ with $85 \%$ ortho-phosphoric acid; B, $2.9 \mathrm{~g} / \mathrm{L}$ sodium dodecyl sulfate:acetonitrile (62:38, v/v) adjusted to $\mathrm{pH} 4.2$ with $85 \%$ ortho-phosphoric acid. The gradient is illustrated in Table 1.

At the end of the gradient program, the column was maintained at the initial conditions for $10 \mathrm{~min}$ before the next injection. The total run time was 40 min.

\subsection{Preparation of stock and working solutions}

A stock solution of each amine was prepared at a final concentration of $1 \mathrm{mg} / \mathrm{mL}$ in $0.1 \mathrm{~N} \mathrm{HCl}$ and further diluted with $0.1 \mathrm{~N} \mathrm{HCl}$ to obtain working solutions in the range $0.1-10.0 \mu \mathrm{g} / \mathrm{mL}$; for synephrine only the range was $5.0-125.0 \mu \mathrm{g} / \mathrm{mL}$. All solutions were stored at $-20{ }^{\circ} \mathrm{C}$ until use.

\subsection{Sample preparation}

About $100 \mathrm{mg}$ of finely ground and homogenized samples were precisely weighed and added to $25 \mathrm{~mL}$ of $0.1 \mathrm{~N} \mathrm{HCl}$ plus $75 \mathrm{~mL}$ of a water:methanol 75:25 solution $(\mathrm{v} / \mathrm{v})$. Extraction efficiency was assessed by preparing PFS samples with and without the addition of $2.5 \mu \mathrm{g} / \mathrm{g}$ of analytes and extracting for $5,10,15,20,25$ and $30 \mathrm{~min}$ under stirring by a magnetic device: 20 min was sufficient for optimal extraction. After extraction, samples were filtered through a $0.45-\mu \mathrm{m}$ filter and injected into the chromatographic equipment.

\subsection{Validation}

A full validation of the method with two detectors was performed according to the current FDA Guidelines on Bioanalytical Method Validation (FDA, 2013).

\subsubsection{System suitability test}

The following parameters were calculated using the ChromNAV software: retention factor $(K)$, separation factor between two neighboring peaks $(\alpha)$, peaks' tailing factor and column efficiency (number of theoretical plates).

\subsubsection{Linearity}

For each run, five standard stock solutions were prepared and analyzed with three independent injections; the concentrations ranged between 5 and $125 \mu \mathrm{g} / \mathrm{mL}$ for synephrine and between 0.1

Table 1

Gradient elution used in HPLC separation.

\begin{tabular}{lcc}
\hline Total time & Phase A (\%) & Phase B (\%) \\
\hline 0 min & 40 & 60 \\
$11 \mathrm{~min}$ & 0 & 100 \\
$25 \mathrm{~min}$ & 0 & 100 \\
$30 \mathrm{~min}$ & 40 & 60 \\
\hline
\end{tabular}



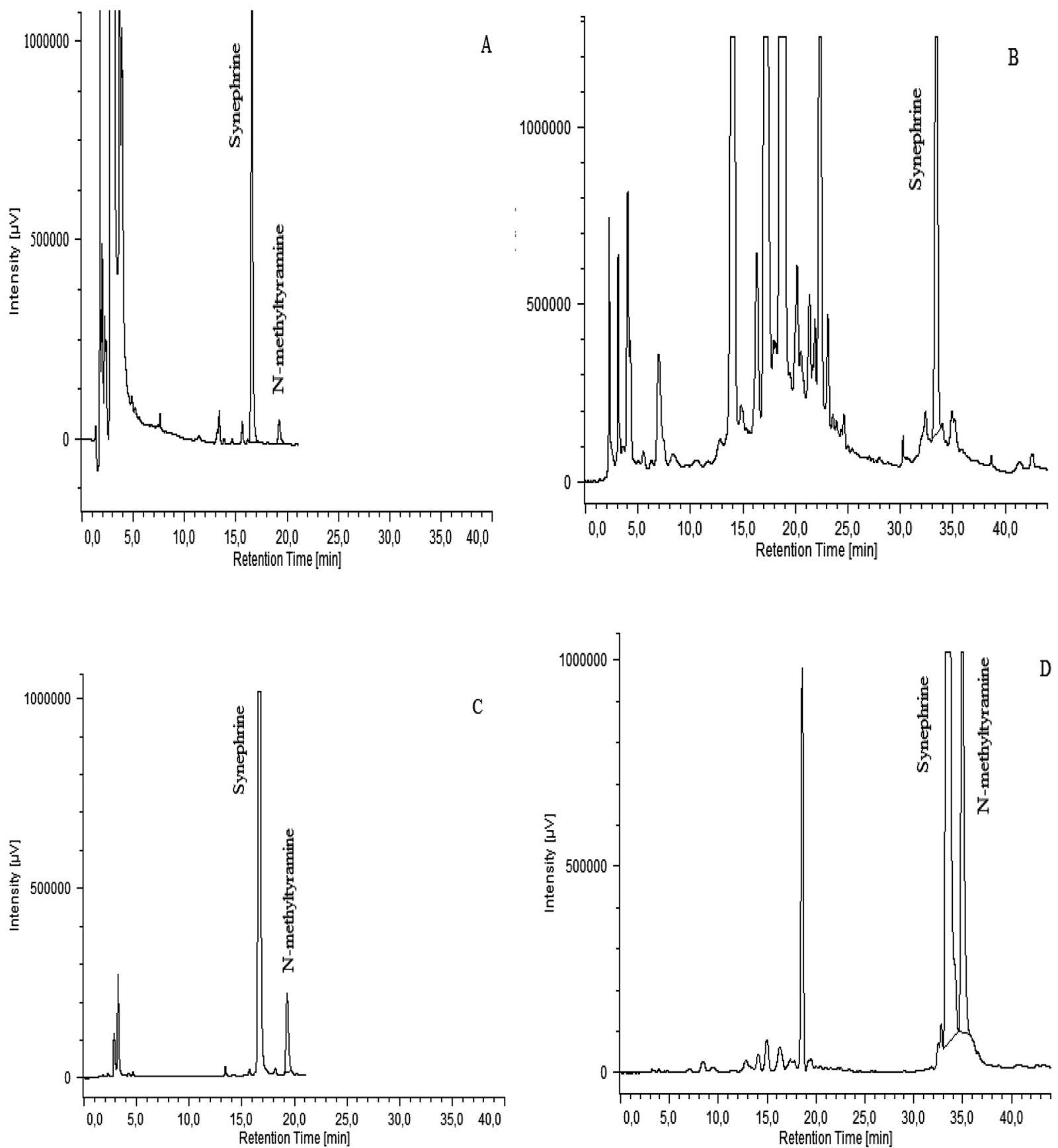

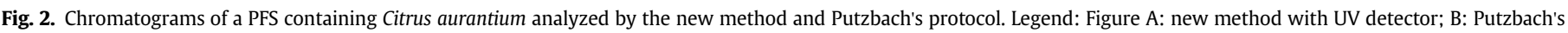
method with UV detector; C: new method with fluorimetric detector; D: Putzbach's method with fluorimetric detector.

Table 2

Results of system suitability tests for the five amines obtained during test analysis $(n=3)$.

\begin{tabular}{|c|c|c|c|c|c|}
\hline & $\begin{array}{l}\text { Retention times }(\mathrm{min}) \\
(\text { mean } \pm \mathrm{SD})\end{array}$ & $\begin{array}{l}K^{\mathrm{a}} \\
(\text { mean } \pm \mathrm{SD})\end{array}$ & $\begin{array}{l}\alpha^{\mathrm{b}} \\
(\text { mean } \pm \mathrm{SD})\end{array}$ & $\begin{array}{l}\text { Symmetry factor } \\
(\text { mean } \pm \text { SD) }\end{array}$ & $\begin{array}{l}\text { Theoretical plates }(N) \\
(\text { mean } \pm \text { SD) }\end{array}$ \\
\hline Octopamine & $17.68 \pm 0.36$ & $8.66 \pm 0.25$ & $1.08 \pm 0.01$ & $0.870 \pm 0.02$ & $42,232 \pm 9582$ \\
\hline Synephrine & $19.00 \pm 0.54$ & $9.37 \pm 0.21$ & $1.08 \pm 0.01$ & $0.903 \pm 0.01$ & $43,208 \pm 8888$ \\
\hline Tyramine & $21.40 \pm 1.00$ & $10.68 \pm 0.19$ & $1.10 \pm 0.01$ & $0.932 \pm 0.04$ & $41,542 \pm 12,798$ \\
\hline $\begin{array}{l}\mathrm{N} \text {-methyl } \\
\text {-tyramine }\end{array}$ & $23.26 \pm 1.28$ & $11.69 \pm 0.27$ & $1.08 \pm 0.01$ & $1.129 \pm 0.004$ & $29,020 \pm 4532$ \\
\hline Hordenine & $24.95 \pm 1.53$ & $12.61 \pm 0.37$ & $1.08 \pm 0.01$ & $1.150 \pm 0.01$ & $15,845 \pm 3635$ \\
\hline
\end{tabular}

\footnotetext{
${ }^{\mathrm{a}} K$ (Retention factor $)=\left(t_{\mathrm{R}}-t_{0}\right) / t_{0}$, where $t_{\mathrm{R}}$ and $t_{0}$ are retention times of sample components and sample solvent, respectively
}

b $\alpha$ (Separation factor) $=\left(t_{\mathrm{R} 2}-T_{0}\right) /\left(t_{\mathrm{R} 1}-t_{0}\right)$, where $t_{\mathrm{R} 2}$ and $t_{\mathrm{R} 1}$ are retention times of two neighboring peaks. 


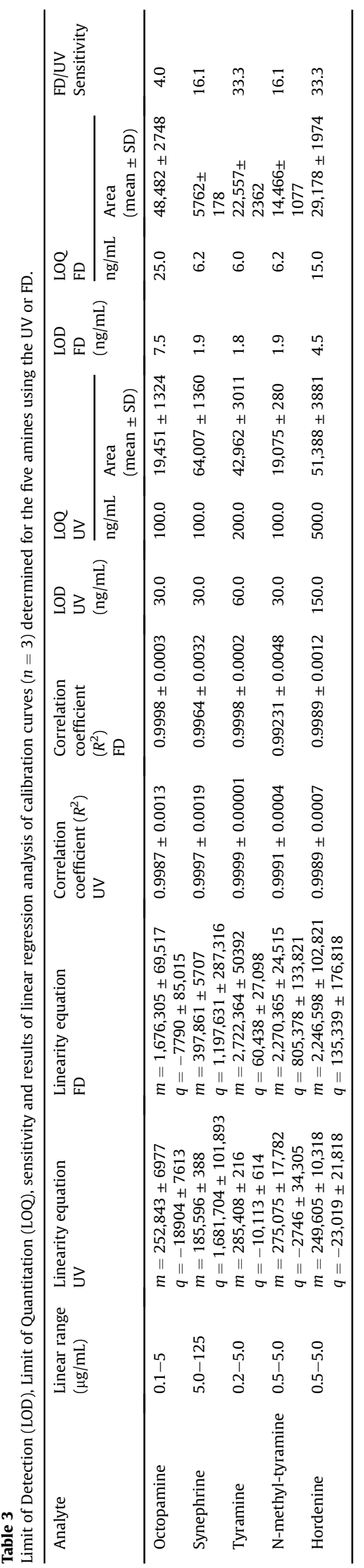

and $5 \mu \mathrm{g} / \mathrm{mL}$ for the other amines. Linear regressions were obtained by plotting the areas of analyte peaks vs the nominal concentrations. The calibration curve equations and the corresponding correlation coefficients $\left(R^{2}\right)$ were calculated using both detectors.

\subsubsection{Limits of Detection and Quantitation}

The Limit of Detection and Quantitation (LOD and LOQ respectively) were determined from calibration curve: the LOQ was defined as the lowest concentration of the calibration curves and was estimated after 5 injections based on a signal-to-noise ratio of 10. A signal-to-noise ratio of 3 was considered acceptable for estimating the LOD.

\subsubsection{Precision}

Intra-day precision was determined by preparing and analyzing, on the same day, five replicates of three different concentrations in the range $0.1-3.0 \mu \mathrm{g} / \mathrm{mL}$ for octopamine, tyramine, $\mathrm{N}$-methyl-tyramine, hordenine and $10.0,40.0,80.0 \mu \mathrm{g} / \mathrm{mL}$ for synephrine.

Inter-day precision was evaluated by repeating the intra-day precision study on five different days. Precision was assessed by calculating the mean, standard deviation (SD), and the coefficient of variation (RSD\%) of these values.

\subsubsection{Accuracy}

Accuracy was determined by evaluating spiked samples with two concentrations of octopamine, tyramine, N-methyl-tyramine, hordenine ( 1.0 and $3.0 \mu \mathrm{g} / \mathrm{mL})$ and synephrine $(8.0$ and $12.0 \mu \mathrm{g} / \mathrm{mL}$ ) and through the calculation of the RSD\% between the calculated and the nominal values.

\subsubsection{Extraction recovery}

A PFS containing only Hypericum perforatum $\mathrm{L}$. was selected as a blank matrix, since it does not contain the investigated amines. The content of ten capsules $(0.5 \mathrm{~g})$ was homogenized, spiked with the standard solutions and extracted as by the described procedure. The recovery for synephrine was carried out at low, medium and high concentrations $(10.0,50.0,100.0 \mu \mathrm{g} / \mathrm{mL})$; for octopamine, tyramine, $\mathrm{N}$-methyl-tyramine, hordenine the concentrations were in the range of $0.1-5.0 \mu \mathrm{g} / \mathrm{mL}$ (three for each amine). Each concentration of both sets was analyzed in three replicates. The percentages of recovery were calculated by comparing the peak area ratio of the analytes measured in the samples to the peak areas of the corresponding standard solutions.

\subsubsection{Stability}

The stability of synephrine stock solutions ( 40.0 and $80.0 \mu \mathrm{g} /$ $\mathrm{mL})$ and of other amines $(2.0$ and $4.0 \mu \mathrm{g} / \mathrm{mL}$ ) was determined on triplicate aliquots which were kept at room temperature for $8 \mathrm{~h}$. Peak areas of these samples were compared with those of freshly prepared stock solutions. Similarly, the stability of the same standard solutions was assessed after storage for 20 days at $-20{ }^{\circ} \mathrm{C}$.

Freeze $\left(-20{ }^{\circ} \mathrm{C}\right)$-thaw stability of these solutions was assessed by comparing their concentrations after three freeze-thaw cycles with the concentrations determined at time zero.

\subsubsection{Specificity}

Potential interference between analytes and endogenous matrix components was investigated by analyzing six batches of Hypericum perforatum L. matrices. Peak areas of compounds coeluting with the analytes should be less than $20 \%$ of the peak area of LOQ samples. 
Table 4

Precision, accuracy and recovery of active amines determined with UV and FD $(n=3)$.

\begin{tabular}{|c|c|c|c|c|c|c|c|c|c|c|c|}
\hline \multirow[t]{2}{*}{ Analyte } & \multicolumn{3}{|c|}{ Intra-day precision (RSD \%) } & \multicolumn{2}{|c|}{ Inter-day precision (RSD \%) } & \multicolumn{3}{|c|}{ Recovery (\%) (mean \pm SD) } & \multicolumn{3}{|c|}{ Accuracy $(\%)($ mean \pm SD $)$} \\
\hline & $(\mu \mathrm{g} / \mathrm{mL})$ & UV & FD & UV & FD & $(\mu \mathrm{g} / \mathrm{mL})$ & UV & FD & $(\mu \mathrm{g} / \mathrm{mL})$ & UV & FD \\
\hline \multirow[t]{3}{*}{ Octopamine } & 0.1 & 7.3 & 7.6 & 7.1 & 9.6 & 0.1 & $104.2 \pm 12.8$ & $107.8 \pm 5.7$ & 1.0 & $96.0 \pm 0.1$ & $98.5 \pm 7.3$ \\
\hline & 2.0 & 3.4 & 5.8 & 3.8 & 5.6 & 1.25 & $89.5 \pm 11.1$ & $90.7 \pm 12.8$ & 3.0 & $103.9 \pm 6.1$ & $105.4 \pm 6.2$ \\
\hline & 3.0 & 6.5 & 6.5 & 10.1 & 13.7 & 5.0 & $101.5 \pm 7.8$ & $102.8 \pm 8.1$ & & & \\
\hline \multirow[t]{3}{*}{ Synephrine } & 10 & 1.3 & 1.2 & 3.3 & 1.3 & 10 & $85.9 \pm 3.0$ & $89.3 \pm 2.6$ & 8.0 & $95.8 \pm 6.9$ & $100.3 \pm 10.8$ \\
\hline & 40 & 5.3 & 2.7 & 5.1 & 2.9 & 50 & $103.4 \pm 14.3$ & $90.3 \pm 8.1$ & 12.0 & $98.9 \pm 5.2$ & $108.2 \pm 4.4$ \\
\hline & 80 & 4.8 & 4.3 & 3.5 & 3.6 & 100 & $96.2 \pm 0.5$ & $102.7 \pm 2.2$ & & & \\
\hline \multirow[t]{3}{*}{ Tyramine } & 0.2 & 5.6 & 4.7 & 8.5 & 9.2 & 0.2 & $97.1 \pm 7.7$ & $103.9 \pm 4.0$ & 1.0 & $99.7 \pm 31$ & $110.3 \pm 7.7$ \\
\hline & 2.0 & 5.0 & 4.6 & 4.0 & 3.8 & 1.25 & $81.4 \pm 0.1$ & $106.2 \pm 2.8$ & 3.0 & $102.5 \pm 9.6$ & $105.6 \pm 5.2$ \\
\hline & 3.0 & 4.6 & 3.8 & 3.9 & 4.3 & 5 & $104.3 \pm 5.5$ & $106.6 \pm 8.6$ & & & \\
\hline \multirow[t]{3}{*}{ N-methyl-tyramine } & 0.5 & 5.6 & 3.9 & 5.5 & 8.2 & 0.5 & $99.0 \pm 1.3$ & $102.1 \pm 6.7$ & 1.0 & $100.0 \pm 4.4$ & $103.7 \pm 5.3$ \\
\hline & 2.0 & 5.0 & 6.8 & 5.8 & 6.2 & 1.25 & $95.8 \pm 6.1$ & $90.1 \pm 6.9$ & 3.0 & $96.9 \pm 5.5$ & $103.8 \pm 5.9$ \\
\hline & 3.0 & 4.6 & 4.4 & 4.5 & 7.3 & 5.0 & $102.1 \pm 4.5$ & $105.7 \pm 4.3$ & & & \\
\hline \multirow[t]{3}{*}{ Hordenine } & 0.5 & 2.8 & 3.2 & 4.8 & 10.7 & 0.5 & $108.4 \pm 6.6$ & $101.9 \pm 11.3$ & 1.0 & $90.2 \pm 4.5$ & $87.8 \pm 8.1$ \\
\hline & 2.0 & 7.6 & 7.9 & 6.7 & 6.2 & 1.25 & $94.5 \pm 3.2$ & $109.5 \pm 4.2$ & 3.0 & $100.0 \pm 0.9$ & $103.2 \pm 8.1$ \\
\hline & 3.0 & 7.8 & 2.8 & 7.0 & 6.4 & 5.0 & $90.5 \pm 5.2$ & $98.9 \pm 4.8$ & & & \\
\hline
\end{tabular}

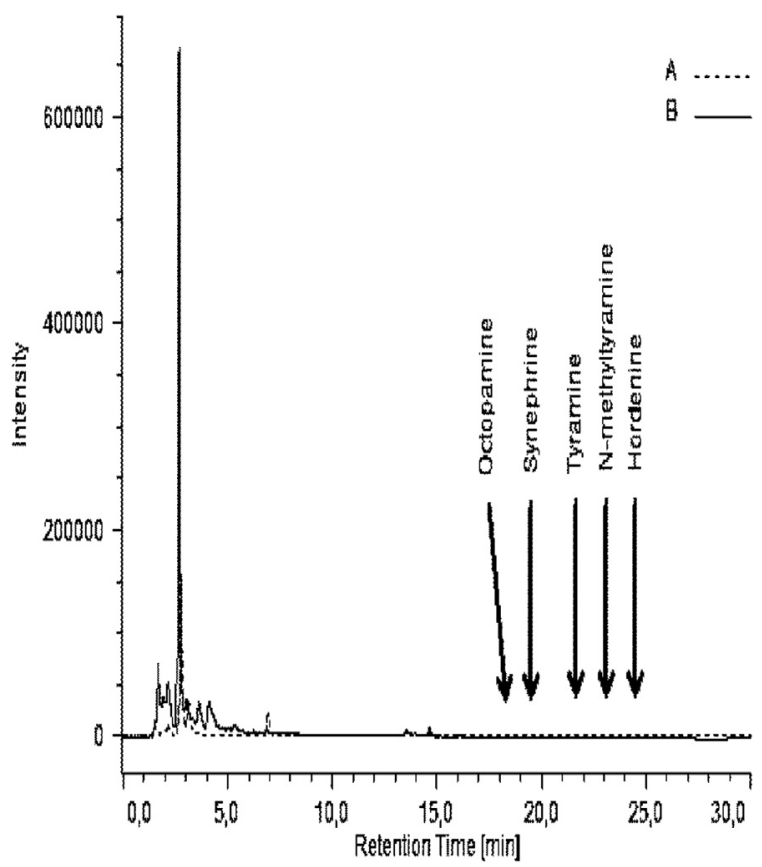

Fig. 3. Chromatogram of a blank extract (Hypericum perforatum L.) analyzed with fluorimetric (A) and UV (B) detector.

\section{Results and discussion}

\subsection{Chromatography}

The first step of the research was the application of known methods (Putzbach et al., 2007; Roman et al., 2004) for the detection of amines in $C$. aurantium, using both raw material and derivatives (extract and PFS). However, these approaches failed to provide an adequate chromatographic resolution probably because of the complexity of the extracted PFS matrices. After experimenting with different gradient conditions, a new ion-pair mobile phase was developed with a binary solvent system as described in Materials and Method. The characteristic analytes of $C$. aurantium (five amines) were well separated within $30 \mathrm{~min}$ at a flow rate of $1 \mathrm{~mL} / \mathrm{min}$ at room temperature.

The chromatographic conditions used in the method here described were very different from those used in all other published methods: gradient elution, the ion-pair technique and the $\mathrm{pH}$ value (4.2). In particular, the $\mathrm{pH} 4.2$ allowed the best separation of interfering peaks, when compared to other elution phases assayed. Fig. 2 shows a comparison between chromatographic separations of a PFS sample by the new developed method (left) and Puzbach's method (right). It is evident that the new method eliminates interferences due to complex matrix.

\subsection{Identification of amines}

The identity of the analytes was established by comparing the peak retention times and Relative Retention Times (RTT) with those of reference standards.

\subsection{System Suitability Test (SST)}

Table 2 shows data on suitability of the chromatographic system. Data obtained with UV and fluorimetric detectors were similar. The considered parameters show that the chromatographic system used in this assay is very efficient. Indeed, it yields retention factors $(K)$ ranging between 8.7 and 12.6 ( $K$ acceptable values $\geq 2$ ) (FDA, 2013) as well as symmetrical, sharp peaks and is therefore suitable for the quantification of the five analytes in complex matrices, such as PFS. Similar data on efficiency and selectivity were also obtained after about 200 injections of samples, showing the long life of the column and the consequent low cost of the assay.

Table 5

Extraction recovery (\%) of active amines $(n=3)$.

\begin{tabular}{|c|c|c|c|c|c|}
\hline Time of extraction (min) & Octopamine & Synephrine & Tyramine & $\mathrm{N}$-methyl-tyramine & Hordenine \\
\hline 20 & $100.48 \pm 2.69$ & $101.88 \pm 2.27$ & $100.3 \pm 2.73$ & $99.79 \pm 3.09$ & $99.92 \pm 3.14$ \\
\hline 15 & $99.97 \pm 1.74$ & $97.8 \pm 3.01$ & $99.81 \pm 2.02$ & $99.45 \pm 2.86$ & $98.9 \pm 2.99$ \\
\hline 10 & $99.83 \pm 3.22$ & $99.85 \pm 2.85$ & $99.70 \pm 1.98$ & $99.34 \pm 2.79$ & $98.9 \pm 3.29$ \\
\hline 5 & $92.49 \pm 2.05$ & $94.33 \pm 1.10$ & $94.75 \pm 2.19$ & $93.8 \pm 2.67$ & $95.02 \pm 3.34$ \\
\hline
\end{tabular}




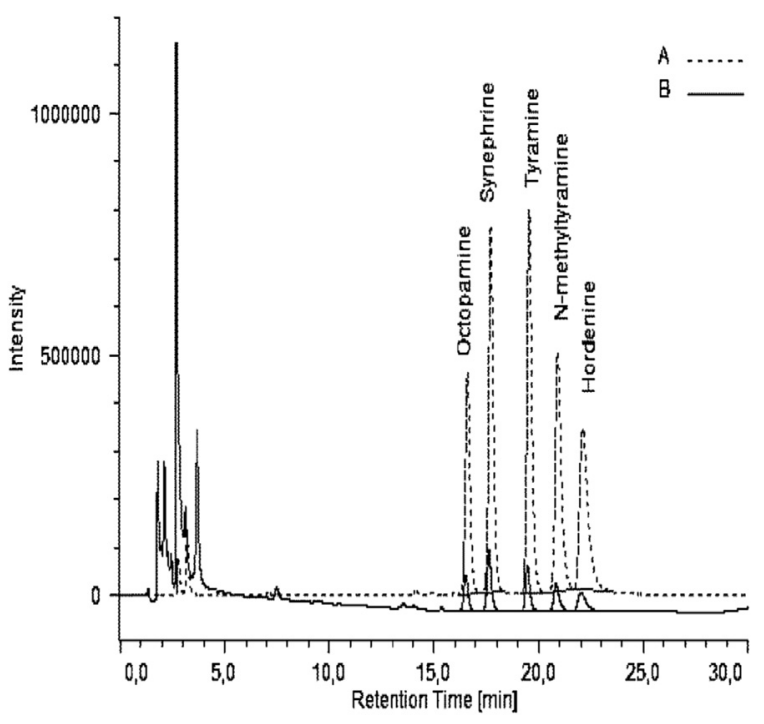

Fig. 4. Chromatogram of a blank extract (Hypericum perforatum L.) spiked with a standard mixture $(10 \mu \mathrm{g} / \mathrm{mL})$ analyzed with fluorimetric (A) and UV (B) detector.

\subsection{Validation}

\subsubsection{Linearity, $L O D$ and $L O Q$}

The method was linear between 5 and $125 \mu \mathrm{g} / \mathrm{mL}$ for synephrine and between 0.1 and $5 \mu \mathrm{g} / \mathrm{mL}$ for other amines, corresponding to the tested concentrations, as shown by the correlation coefficients $\left(R^{2}\right)$ being always greater than 0.99 . Table 3 shows the linearity results (no significant variation of the slope between calibration curves, RSD being between 0.08 and $6.5 \%$, as well as the Limit of Detection (LOD) and Limit of Quantitation (LOQ) values: LOD obtained by fluorescence detector was between 1.8 and $7.5 \mathrm{ng} / \mathrm{mL}$ and LOQ was between 6.0 and $25.0 \mathrm{ng} / \mathrm{mL}$ for tyramine and octopamine respectively. The fluorimetric detection was 4-30 times as sensitive as UV detection. These ranges of sensitivity were in every case suitable for accurate determination of the amines in C. aurantium samples.

\subsubsection{Precision, accuracy, specificity and recovery}

Table 4 shows the results of precision, accuracy and recovery experiments. Intra- and inter-day precision data showed RSD\% values always $<15 \%$ so that the method is precise, and as the
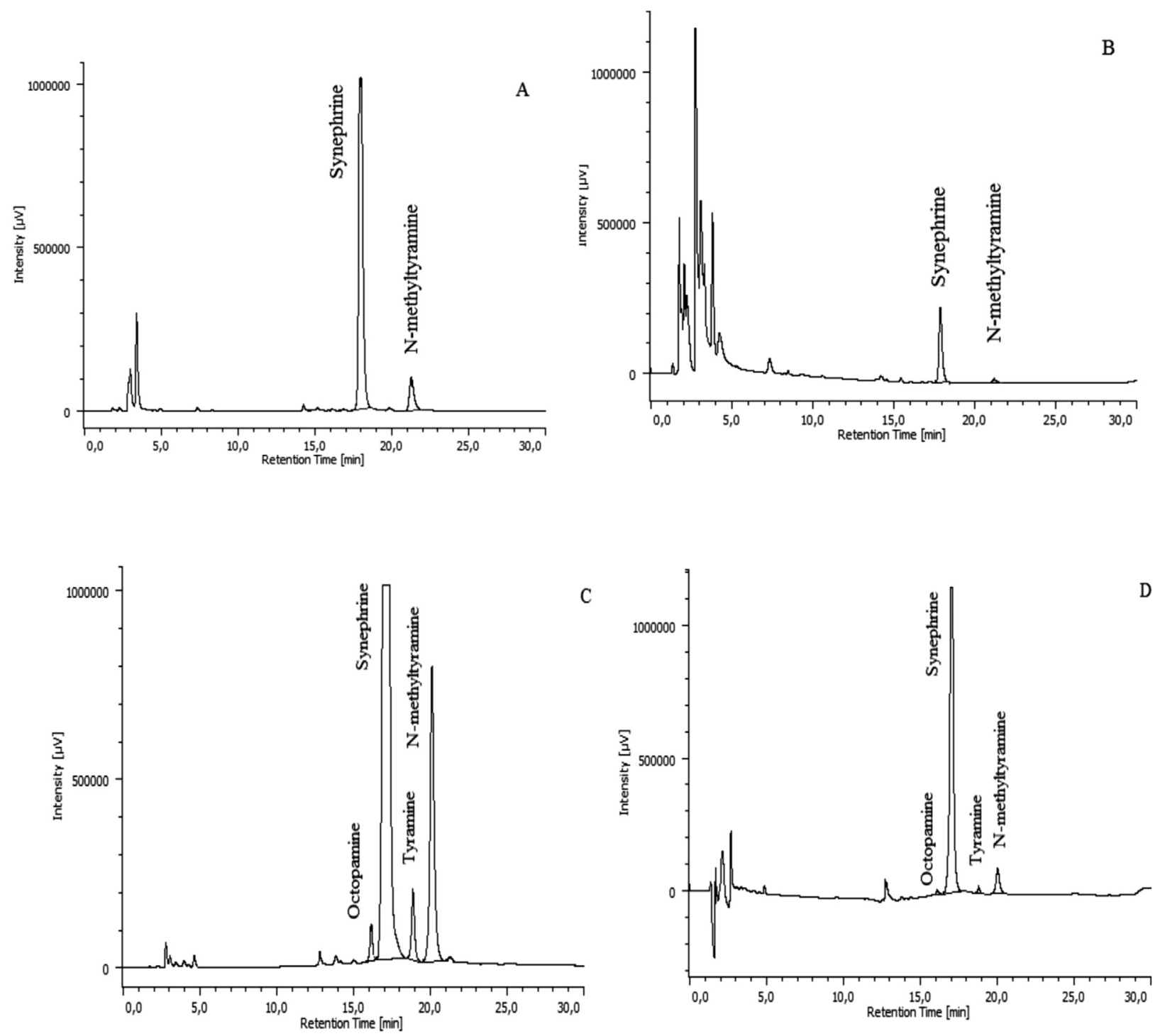

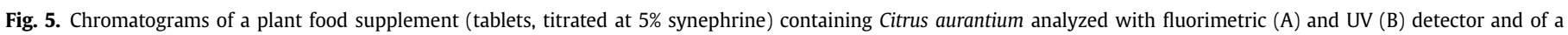
C. aurantium extract revealed with fluorimetric (C) and UV (D) detector. 
calculated accuracy was always within $15 \%$ of the nominal concentration, the method can be considered accurate. A blank sample containing only $H$. perforatum $\mathrm{L}$. was tested to confirm the absence of peaks having retention times similar to those of $C$. aurantium amines (Fig. 3). No peak at the retention times of the amines had an area exceeding $20 \%$ of LOQ values. The recovery with both detection systems ranged between 80 and $110 \%$ for all amines.

\subsubsection{Stability}

Stock solutions of synephrine, octopamine, tyramine, N-methyltyramine and hordenine were stable for at least $24 \mathrm{~h}$ at room temperature: the peak areas in the stock standard solution compared with those for freshly prepared solution ranged between $99.50 \% \pm 3.6$ and $91.0 \% \pm 3.2$ for UV detector and between $90.5 \% \pm 3.8$ and $104.2 \% \pm 0.5$ for the fluorimetric detector. The same stock solutions were stable for at least 1 month at $-20^{\circ} \mathrm{C}$ : the longterm stability ranged between $91.4 \% \pm 5.9$ and $102.2 \% \pm 3.7$ for the UV detector and between $90.8 \% \pm 5.9$ and $108.9 \% \pm 5.6$ for the fluorimetric detector.

Freeze/thaw stability experiments showed that the analytes were stable in $0.1 \mathrm{~N} \mathrm{HCl}$ for at least three freeze-thaw cycles at $-20{ }^{\circ} \mathrm{C}$ : the stability ranged between $91.9 \% \pm 1.3$ and $101.9 \% \pm 2.5$ for the UV detector and between $91.9 \% \pm 1.1$ and $107.8 \% \pm 2.2$ for the fluorimetric detector.

Stability of the 5 amines in the final extract was at least $48 \mathrm{~h}$ at $4{ }^{\circ} \mathrm{C}$.

\subsection{Application of the method}

\subsubsection{Optimization of time extraction}

Spiked blank samples analyzed after different extraction times showed that the recovery of the analytes reached a percentage close to $100 \%$ after 20 min of magnetic stirring (Table 5). Therefore, all analyzes were performed using that extraction-time.

\subsubsection{Applicability}

The applicability of the method was finally verified by using both a blank matrix of $H$. perforatum L. and two real samples (a C. aurantium extract and a commercial PFS). Standard stock solutions $(10 \mu \mathrm{g} / \mathrm{mL})$ of the amines were added to the blank matrix in order to evaluate peak separation and method suitability. Figs. 4 and 5 show the resulting chromatograms, where separation was highly satisfactory in all the samples.

\section{Conclusion}

This paper describes the development, validation and application of a LC/UV/Fluorescence assay for quantitative analysis of five active amines in $C$. aurantium raw material and derivatives. The method has been fully validated according to FDA Guidelines for Bioanalytical Method Validation (FDA, 2013) showing accurate, precise, selective, fast and relatively inexpensive analyzes. The quantification of these amines is particularly important since their concentrations in PFS are regulated by national and international laws and for post-market control of undeclared illegal addition of synephrine and octopamine. The improved chromatographic system and the use of a fluorescence detector provide a validated tool to analyze the five active amines in complex matrices, including plant food supplements.

\section{Acknowledgments}

The research leading to these results has received funding from the European Community's Seventh Framework Program (FP7/ 2007-2013) under grant agreement $n^{\circ} 245199$. It has been carried out within the PlantLIBRA project (website: www.plantlibra.eu). This report does not necessarily reflect the Commission's views or its future policy on this area.

\section{References}

Angell, M., \& Kassirer, J. P. (1998). Alternative medicine - the risks of untested and unregulated remedies. The New England Journal of Medicine, 339, 839-841.

Arbo, M. D., Larentis, E. R., Linck, V. M., Aboy, A. L., Pimentel, A. L., Henriques, A. T., et al. (2008). Concentrations of p-synephrine in fruits and leaves of Citrus species (Rutaceae) and the acute toxicity testing of Citrus aurantium extract and p-synephrine. Food and Chemical Toxicology, 46, 2770-2775.

Cianchino, V., Acosta, G., Ortega, C., Martínez, L. D., \& Gomez, M. R. (2008) Analysis of potential adulteration in herbal medicines and dietary supplements for weight control by capillary electrophoresis. Food Chemistry, 108, 1075-1081.

FDA - Food and Drug Administration. (2013). Guidance for industry - Bioanalytical method validation. Food and Drug Administration Accessed on October 2013 http://www.labcompliance.de/documents/FDA/FDA-Others/Laboratory/f-507bioanalytical-4252fnl.pdf.

Gurley, B. J., Gardner, S. F., \& Hubbard, M. A. (2000). Content versus label claims in ephedra-containing dietary supplements. American Journal of Health-System Pharmacy, 57, 963-969.

Gurley, B. J., Wang, P., \& Gardner, S. F. (1998). Ephedrine-type alkaloid content of nutritional supplements containing Ephedra sinica (Ma-huang) as determined by high performance liquid chromatography. Journal of Pharmaceutical Sciences, $87,1547-1553$

Haller, C. A., \& Benowitz, N. L. (2000). Adverse cardiovascular and central nervous system events associated with dietary supplements containing ephedra alkaloids. The New England Journal of Medicine, 343, 1833-1838.

Hung, S. K., Hillier, S., \& Ernst, E. (2011). Case reports of adverse effects of herbal medicinal products (HMPs): a quality assessment. Phytomedicine, 18, 335-343.

Italian Ministry of Health. (09 July 2012). Disciplina dell'impiego negli integratori alimentari di sostanze e preparati vegetali (Regulation on the use of botanicals and botanical preparations in food supplements). In Gazzetta Ufficiale n. 169. http://www.gazzettaufficiale.it/atto/stampa/serie_generale/originario (Accessed on October 2013).

Niemann, R. A., \& Gay, M. L. (2003). Determination of ephedrine alkaloids and synephrine in dietary supplements by column-switching cation exchange highperformance liquid chromatography with scanning-wavelenght ultraviolet and fluorescence detection. Journal of Agricultural and Food Chemistry, 51 5630-5638.

Pellati, F., Benvenuti, S., Melegari, M., \& Firenzuoli, F. (2002). Determination of adrenergic agonists from extracts and herbal products of Citrus aurantium L. var. amara by LC. Journal of Pharmaceutical and Biomedical Analysis, 29 $1113-1119$.

Penzak, S. R., Jann, F. C. P., Cold, J. A., Hon, Y. Y., Desai, H. D., \& Gurley, B. J. (2001). Seville (sour) orange juice: synephrine content and cardiovascular effects in normotensive adults. The Journal of Clinical Pharmacology, 41, 1059-1063.

Putzbach, K., Rimmer, C. A., Sharpless, K. E., \& Sander, L. C. (2007). Determination of bitter orange alkaloids in dietary supplements standard reference materials by liquid chromatography with ultraviolet absorbance and fluorescence detection. Journal of Chromatography A, 1156, 304-311.

Roman, M. C., Gray, D., Luo, G., McClanahan, R., Perez, R., Roper, C., et al. (2004). Determination of ephedrine alkaloids in botanicals and dietary supplements by HPLC-UV. The Journal of AOAC International, 87, 1-14.

Stohs, S. J., Preuss, H. G., Keith, S. C., Keith, P. L., Miller, H., \& Kaats, G. R. (2011) Effects of $p$-synephrine alone and in combination with selected bioflavonoids on resting metabolism, blood pressure, heart rate and self-reported mood changes. International Journal of Medical Sciences, 8, 295-301.

Vaysse, J., Balayssac, S., Gilard, V., Desoubdzanne, D., Malet-Martino, M., \& Martino, R. (2010). Analysis of adulterated herbal medicines and dietary supplements marketed for weight loss by DOSY ${ }^{1} \mathrm{H}-\mathrm{NMR}$. Food Additives \& Contaminants. Part A, Chemistry, Analysis, Control, Exposure \& Risk Assessment, 27, 903-916. 